\title{
Short-term and long-term outcomes for congenital cardiac surgery
}

I N this issue of Cardiology in the Young, We publish a paper by Jacobs and colleagues ${ }^{1}$ that reviews the short-term mortality following cardiac surgery for congenital heart disease in Florida between 2003 and 2006. The overall discharge mortality for the eight Florida surgical centres $(3.8 \%)$ did not differ from national outcomes and none of the eight Florida centres were significant outliers judged by 95\% confidence intervals. This remained true when outcomes were assessed in the context of the complexity of individual procedures. The authors of the paper stress the importance of collaboration between surgical centres and common learning through such mechanisms as mentorship, bidirectional visits between centres and joint case conferences. The work being undertaken in Florida is impressive and shows a strong, shared commitment to achieve the best possible outcomes for children with congenital heart disease.

This report raises again two of the issues I have discussed previously in this column. Firstly, it highlights the importance of the open reporting of outcomes. ${ }^{2}$ Secondly, it raises the subject of the configuration and size of surgical units. Several years ago, I wrote in this column a review of the evidence that workload of paediatric cardiac surgical units was an important determinant of outcomes. ${ }^{3}$ The evidence at that stage was not decisive, but it existed and as I said in the article "there is a great deal of evidence that we cannot ignore." At the time, I was writing about the initiative here in the United Kingdom to reconfigure cardiac surgical centres. Since I wrote those words, much progress has been made in the United Kingdom with the open publication of results, but the configuration of centres has largely remained the same. In the intervening years, the evidence has become much stronger and now there is little doubt that for paediatric cardiac centres a critical mass of activity is required to be confident of sustainably achieving the best outcomes. The latest of a series of papers that have found a consistent relationship between outcome and workload for paediatric cardiac surgery was published earlier this year. ${ }^{4}$ For complex conditions, there is now clear evidence that only those centres undertaking surgery for those conditions frequently can be confident that they are achieving the best outcomes for their patients. Those planning the configuration of paediatric cardiac surgical centres must take this evidence into account, but it also must drive collaboration between different units. It is good to see that the centres in Florida are already acting on this.

In this issue of the journal there are also three articles looking at different aspects of the long-term outcome for patients who have undergone Fontan like procedures for palliation of a single ventricular circulation. The long-term management of this group of patients remains a particular challenge in the management of congenital cardiac disease.

Williams and colleagues ${ }^{5}$ investigated the pre and post-operative factors that predict the longterm functional outcome for this group of patients. Systemic ventricular characteristics and function, preoperative oxygen saturation and postoperative arrhythmias were found to predict functional outcome an average of 8.7 years after the procedure. Interestingly while these factors were found partially to predict functional outcome, they could not account for the majority of variation in outcome. Klimes and colleagues ${ }^{6}$ found that patients who had their definitive surgery at a younger age had better exercise capacity when assessed an average 6.9 years after surgery. They also demonstrate that exercise capacity was a good predictor of systemic ventricular function measured by functional magnetic resonance imaging.

Ovaert and colleagues ${ }^{7}$ report the effects of using the endothelin receptor antagonist, bosentan, in patients with "failing" Fontan circulations. Their study did demonstrate some improvements in oxygen saturations in some of their patients, but overall there was no improvement in the group after three months of treatment. As this highlights, 
the role of pulmonary vascular disease in patients who have undergone Fontan like procedures is not well understood. Also in this issue, Berger points out in his editorial, ${ }^{8}$ pulmonary hypertension and its interaction with congenital cardiac defects is not well understood at all. It is in this context that we are publishing a further article in our series on pulmonary hypertension taken from our on-line supplement. In the latest article in this series, Adatia and Beghetti discuss the early post-operative care of patients with pulmonary hypertension. ${ }^{9}$ You can find the full on-line supplement, which includes a comprehensive review of what we do know about pulmonary hypertension and its role in patients with congenital cardiac defects, including consideration of pulmonary vascular disease in patients with a single ventricular circulation, at our website: http://journals.cambridge.org/CTY.

Edward Baker Editor-in-Chief

E-mail: ctyeditor@cambridge.org

\section{References}

1. Jacobs JP, Quintessenza JA, Burke RP, et al. Analysis of regional congenital cardiac surgical outcomes in Florida using The Society of Thoracic Surgeons Congenital Heart Surgery Database. Cardiol Young 2009; 19: 360-369.

2. Baker E. Quality is measured by more that the clinical outcome. Cardiol Young 2008; 18: 449-450.

3. Baker E. The greatest good to the greatest number. Cardiol Young 2002; 12: 209-210.

4. Welke KF, O'Brien SM, Peterson ED, et al. The complex relationship between pediatric cardiac surgical case volumes and mortality rates in a national clinical database. J Thorac Cardiovasc Surg 2009; 137: 1133-1140.

5. Williams I, Sleeper L, Colan S, et al. Functional state following the Fontan procedure. Cardiol Young 2009; 19: 320-330.

6. Klimes K, Ovroutski S, Abdul-Khaliq H, et al. Exercise capacity reflects ventricular function in patients having the Fontan circulation. Cardiol Young 2009; 19: 340-345.

7. Ovaert C, Thijs D, Dewolf D, et al. The effect of bosentan in patients with a failing Fontan circulation. Cardiol Young 2009; 19: 331-339.

8. Berger MF. Pulmonary hypertension associated with congenital cardiac disease. Cardiol Young 2009; 19: 311-314.

9. Adatia I, Beghetti M. Early postoperative care of patients with pulmonary hypertension associated with congenital cardiac disease. Cardiol Young 2009; 19: 315-319. 